\title{
Price Impact Asymmetry of Block Trades: An Institutional Trading Explanation
}

\author{
Gideon Saar ${ }^{1}$ \\ First Draft: April 1997 \\ Current version: October 1999
}

${ }^{1}$ Stern School of Business, New York University, 44 West Fourth Street, Suite 9-93, New York, NY 10012-1126. Tel: 212-998-0318. Fax: 212-995-4233. E-mail: gsaar@stern.nyu.edu. I wish to thank David Easley, Lawrence Glosten (the editor), Gustavo Grullon, Robert Jarrow, Roni Michaely, Maureen O'Hara, Duane Seppi, Seymour Smidt, Matthew Spiegel, Bhaskaran Swaminathan, Soeren Hvidkjaer, an anonymous referee, and participants in Cornell University's Finance Workshop, the 1998 Accounting and Finance Conference at Tel Aviv University, and the 1999 American Finance Association meetings for helpful comments. 


\begin{abstract}
Empirical research in finance documented the existence of a permanent price impact asymmetry between buyer and seller-initiated block trades: the permanent price impact of buys is larger than that of sells. This paper develops a theoretical model to explain and investigate the asymmetry phenomenon. The model formalizes an intuition that the dynamic trading strategy of profit-maximizing institutional portfolio managers creates a difference between the information content of buys and sells. It is this difference that causes the expected permanent price impact asymmetry. The model produces new empirical implications concerning the relationship between the asymmetry phenomenon and the economic environment. The main implication of the model is that the history of price performance influences the asymmetry. The longer the run-up in a stock's price, the less is the asymmetry. The greater the trading intensity of institutional investors or the more "informationally-active" a stock, the more pronounced is the asymmetry when a stock's price has not been going up or is at the beginning of a price run-up. The opposite result appears after a long period of (abnormal) price appreciation.
\end{abstract}




\section{Price Impact Asymmetry of Block Trades: An Institutional Trading Explanation}

Empirical research on block transactions and institutional trades has produced a seemingly puzzling result: markets react differently to buy and sell orders. Beginning with Kraus and Stoll (1972), researchers have found that block purchases have a larger permanent price impact than block sales (Holthausen, Leftwich and Mayers, 1987, 1990; Keim and Madhavan, 1996; Gemmill, 1996). The same result was documented for institutional trades (Chan and Lakonishok, 1993) and for institutional trade packages (Chan and Lakonishok, 1995). While prices go up on buys and down on sells, they revert after sells but remain high after buys, creating the permanent price impact asymmetry.

Two explanations appear in the literature to account for the permanent price impact of block trades: inelastic demand and supply curves, and information effects. If a stock does not have sufficiently close substitutes, the excess demand and supply curves for its shares will not be perfectly elastic and block trades will have a permanent price impact. No obvious story, however, can explain why the long-term elasticity of demand in a secondary market should differ than that of supply. Hence, it is unclear why the permanent price impact should depend on whether the initiator of a transaction was a buyer or a seller. ${ }^{1}$ On the other hand, if informed traders are active in the market and their trading strategy makes buy orders carry more information than sell orders, equilibrium prices should adjust more for buys than for sells.

One possible reason for differences in the information content of trades is mentioned by Chan and Lakonishok (1993): "Since an institutional investor typically does not hold the market portfolio, the choice of a particular issue to sell, out of the limited alternatives in a

\footnotetext{
${ }^{1}$ Short-run liquidity costs were used in the literature to explain the temporary impact of block trades. Temporary asymmetry between buys and sells was attributed to the willingness of block positioning firms to accommodate sales but not purchases (Kraus and Stoll, 1972), and to difficulty in locating potential sellers as opposed to potential buyers (Chan and Lakonishok, 1993). Holthausen et al. (1987) report that discussions with block traders suggest that they do in fact often accommodate block purchases. Analysis of commissions by Keim and Madhavan (1994) suggests that differences in the cost of locating counter-parties cannot explain the asymmetry in the price impact of buys and sells. While it may be that short-run liquidity concerns affect the prices at which blocks trade, they cannot explain why the permanent price impact of buys and sells differ.
} 
portfolio, does not necessarily convey negative information... As a result, there are many liquidity-motivated reasons to dispose of a stock. In contrast, the choice of one specific issue to buy, out of the numerous possibilities on the market, is likely to convey favorable firmspecific news." (p. 185) Implicit in this argument are numerous assumptions about both the set of feasible investment strategies that can be employed by mutual funds and their optimal trading strategy. Without being specific about the underlying mechanism that generates informational differences between buys and sells, we cannot hope to test the information explanation. An investigation of the permanent price impact asymmetry therefore requires setting forth a basic set of assumptions on the behavior of institutional investors, generating informational differences between buys and sells, and relating them to other phenomena in the market in order to produce new testable implications. The objective of this paper is to pursue this line of investigation.

More specifically, I make four observations concerning the behavior and constraints of mutual funds. ${ }^{2}$ First, they often devote substantial resources to gathering and analyzing information. Second, most mutual funds limit their investment to money they receive from shareholders (rather than borrow). Hence, investing in one stock has the opportunity cost of not investing in another. Third, mutual funds do not concentrate their holdings in only a few stocks. Fourth, mutual funds hold assets in non-negative amounts. In other words, they seem to be averse to extensive usage of short sales. These four characteristics of institutional behavior create a situation in which portfolio managers are predominantly engaged in searching for stocks whose price is expected to rise. They re-balance their portfolios frequently to sell stocks that do not fit this description.

I explicitly model an institutional dynamic trading strategy consistent with these four observations. The model highlights the considerations of portfolio managers who are looking to exploit information in a multiple-stock context and are subject to some constraints on their allowable trading strategies. Their expected profit maximizing trading strategy involves

\footnotetext{
${ }^{2}$ The terms "institutional investors" and "mutual funds" are used in this paper interchangeably. A more elaborate discussion of these observations (with references) is provided in Section 2.1.
} 
always searching for information about stocks already in their portfolios in order to sell stocks whose price is expected to go down or on which there is no special information. Their search for information continues among stocks not in their portfolios in order to buy stocks on which they discover favorable information. If the market knows that institutional investors may be informed about the prospects of stocks, such a dynamic re-balancing strategy creates a difference between the information content of buys and sells.

I investigate how the behavior of institutional investors affects the market using a simple intertemporal trading model. The expected permanent price impact of a block trade in the model corresponds to the change in the market's expectations of the true value of a stock brought about by the block transaction. I derive an expression for the expected permanent price impact asymmetry between buyer and seller-initiated block transactions and explore its relationship with the economic environment. The model demonstrates how the price impact asymmetry that was documented in the empirical studies can arise. More importantly, the model produces new empirical implications concerning the influence of price performance, institutional following, information intensity, and volatility on the asymmetry phenomenon.

The main implication of the model is that the history of price performance influences the asymmetry. The longer the run-up in a stock's price, the less is the asymmetry. In fact, the model predicts no asymmetry or even negative asymmetry - sells having a larger permanent price impact than buys - following a long (abnormal) price run-up. In addition, past price performance affects the manner in which other elements of the economic environment relate to the asymmetry phenomenon. For example, the greater the trading intensity of institutional investors, the more pronounced is the asymmetry when the stock's price has not been rising or when the stock is at the beginning of a price run-up. The opposite result appears after a long period of (abnormal) price appreciation. A similar relationship also exists between the frequency of information events concerning the stock and the asymmetry: the more "informationally-active" a stock, the greater is the asymmetry if the stock's price has not been going up or is at the beginning of a series of price appreciations. The opposite 
result appears after a long price run-up. While the required return always increases the asymmetry, greater dispersion of a stock's price increases the asymmetry at the beginning of a price run-up, but decreases it after a long period of price appreciation.

The implications of the model concerning the relation between the permanent price impact asymmetry and the economic environment have not been tested by the empirical papers that documented this phenomenon. Hence, they provide an opportunity to test the hypothesis that the asymmetry phenomenon arises due to the behavior of institutional investors. Previous theoretical models of block trades (e.g., Easley and O'Hara, 1987; Seppi, 1990) focus on the choice of traders over which trade size to use but make no attempt to explain the price impact asymmetry. Other related papers are Bhattacharya and Krishnan (1999), who explore how suspicion in capital markets may alleviate moral hazard in managerial disclosure and produce a difference in the information content of buys and sells, and Allen and Gorton (1992), who investigate market manipulation using exogenous asymmetry in the arrival rates of uninformed buyers and sellers.

The rest of the paper is organized as follows. Section 1 defines the permanent price impact asymmetry. Section 2 describes the trading strategy of institutional investors and sets up the trading model. Section 3 investigates the asymmetry phenomenon in this economy and discusses the empirical implications. Section 4 is a conclusion.

\section{Permanent Price Impact Asymmetry}

The empirical literature on the price impact of block trades focuses on investigating three basic prices: a proxy for the equilibrium price prior to the block trade $\left(P_{-1}^{e}\right)$, the price at which the block trade is executed $\left(P^{T}\right)$, and a proxy for the equilibrium price following the block trade $\left(P_{+1}^{e}\right)$. The permanent price impact of a buyer-initiated block trade is defined as $\Delta B=\frac{P_{+1}^{e}-P_{-1}^{e}}{P_{-1}^{e}}$ conditional on the execution of a block trade in the period bracketed by these two equilibrium prices. Hence, the permanent price impact is not a function of the block's actual trading price. Instead, it is a random variable assumed to represent the 
possible changes in equilibrium value conditional on the information that can be inferred from the block. The fact that an investor wants to trade a block alters beliefs about the value of the stock. If some investors possess private information and use it optimally, the expected permanent price impact of a buyer-initiated block trade will most likely be positive. In contrast, the expected permanent price impact of a seller-initiated block trade will be negative. To make the comparison of magnitudes easier, the permanent price impact of a seller-initiated block trade is defined as $\Delta S=\frac{P_{-1}^{e}-P_{+1}^{e}}{P_{-1}^{e}}$. Hence, the expected price impact of seller-initiated block trades is also positive.

A theoretical investigation of the price impact asymmetry requires more specific definitions of the value process of stocks and the pre and post-trade equilibrium prices. There are $N$ stocks in the economy, each representing a claim to the assets of a firm. The true value of stock $i$ is defined as the discounted value of all future gains or losses of firm $i$. A bad event on date $t$ implies a loss of $Z_{t}^{i}$ (a strictly positive number) and occurs with probability $\delta^{i}$. A good event on date $t$ implies a gain of the same magnitude, $Z_{t}^{i}$, and occurs with probability $1-\delta^{i}$. Information about the gains or losses reaches the market with probability $\alpha^{i}$. On dates without information, the market assumes that gains (or losses) are at their expected value, $\left(1-2 \delta^{i}\right) Z_{t}^{i}{ }^{3}$ Private information is short lived and the nature of the information event is revealed to all after the end of trading on date $t$. For the ease of exposition, each date will be referred to as a "day." 4

The required return on each stock, $r^{i}$, is the result of an equilibrium (or the absence of arbitrage) along the lines of traditional asset pricing models. In other words, investors in the market agree on the model for long term valuation of stocks. Every evening when all investors have the same information set, they reach the same conclusions as to the values of

\footnotetext{
${ }^{3}$ This information structure is similar to the one used in Easley and O'Hara (1992) which includes event uncertainty in addition to uncertainty with respect to the nature of the event.

${ }^{4}$ If one believes that relevant information arrives only once a week or once a month, one can simply relabel the time intervals accordingly. What is important to the analysis is the discrete nature of information arrival and that old information is completely revealed before new information arrives. This issue is further discussed in Section 3.2.
} 
all stocks. ${ }^{5}$ Investors value each stock under the assumption that $\alpha^{i}, \delta^{i}$, and $r^{i}$ are constant for a finite horizon of $T^{i}$ days. ${ }^{6}$ Let $\mathcal{F}_{t}$ be the information set used by the market to value stocks at the end of each day (i.e., $\mathcal{F}_{t}$ includes all parameters of the economy and past realizations of the information events). Then, the true value of stock $i$ on date $t<T^{i}$ is:

$$
V_{t}^{i}=\left(1+r^{i}\right)^{t} E\left[C_{0}^{i}+\sum_{s=1}^{T^{i}} \frac{e_{s}^{i}}{\left(1+r^{i}\right)^{s}} \mid \mathcal{F}_{t}\right]
$$

where,

$$
e_{t}^{i}=\left\{\begin{array}{rll}
Z_{t}^{i} & \text { with probability } & \alpha^{i}\left(1-\delta^{i}\right) \\
-Z_{t}^{i} & \text { with probability } & \alpha^{i} \delta^{i} \\
\left(1-2 \delta^{i}\right) Z_{t}^{i} & \text { with probability } & 1-\alpha^{i}
\end{array}\right.
$$

and the role of $C_{0}^{i}$ is to capture accrual earnings, investment costs prior to date zero, and the market's best-effort assessment of the discounted value of future cash flows beyond $T^{i}$. Under this structure, the discounted true value process is a martingale with respect to $\mathcal{F}_{t}$, and the expression for the value of stock $i$ can be rearranged to emphasize the change in value over days:

$$
V_{t}^{i}=V_{t-1}^{i}\left(1+r^{i}\right)+e_{t}^{i}-\left(1-2 \delta^{i}\right) Z_{t}^{i}
$$

Expression (1) shows how in addition to the required return earned by the stock every day, the stock's value will go up by $2 \delta^{i} Z_{t}^{i}$ on days with good information events, go down by $2\left(1-\delta^{i}\right) Z_{t}^{i}$ on days with bad information events, and stay the same on days without information events.

The empirical papers mentioned in the introduction differ in terms of the proxies used for the equilibrium prices. Following Kraus and Stoll (1972), I define $P_{-1}^{e}$ as the closing price on day $t-1$. In the context of the model presented here, the actual price of the last trade is not known for sure. Hence, $P_{-1}^{e}$ is taken to be the price after the close on day $t-1, V_{t-1}^{i}$. Similarly, the equilibrium price following the block transaction, $P_{+1}^{e}$, is defined as the price after the close on day $t, V_{t}^{i}$. Using these definitions, the permanent price impact of a block

\footnotetext{
${ }^{5}$ While the model that gives rise to the required return is not explicitly written down in this paper, it can be thought of as one of the standard asset pricing models that describe a world of homogeneous information.

${ }^{6} T^{i}$ is determined based on how strong are beliefs in the market that firm $i$ will continue to perform according to the current parameters.
} 
buy at the opening of the market on day t can be written as:

$$
\Delta B^{i}=\left\{\begin{array}{lll}
\frac{V_{t-1}^{i}\left(1+r^{i}\right)+Z_{t}^{i}-\left(1-2 \delta^{i}\right) Z_{t}^{i}-V_{t-1}^{i}}{V_{t-1}^{i}}=r^{i}+2 \delta^{i} \frac{Z_{t}^{i}}{V_{t-1}^{i}} & \text { w.p. } P\left(H^{i} \mid \mathcal{F}_{t-1}, B^{i}\right) \\
\frac{V_{t-1}^{i}\left(1+r^{i}\right)-V_{t-1}^{i}}{V_{t-1}^{i}} & =r^{i} & \text { w.p. } P\left(O^{i} \mid \mathcal{F}_{t-1}, B^{i}\right) \\
\frac{V_{t-1}^{i}\left(1+r^{i}\right)-Z_{t}^{i}-\left(1-2 \delta^{i}\right) Z_{t}^{i}-V_{t-1}^{i}}{V_{t-1}^{i}} & =r^{i}-2\left(1-\delta^{i}\right) \frac{Z_{t}^{i}}{V_{t-1}^{i}} & \text { w.p. } P\left(L^{i} \mid \mathcal{F}_{t-1}, B^{i}\right)
\end{array}\right.
$$

where the events $H^{i}, O^{i}$ and $L^{i}$ represent good information, no information and bad information, respectively, about firm $i$, and $B^{i}$ in the conditioning information set represents the arrival of a buy order for a block of firm $i$ 's stock. The price impact of seller-initiated blocks, $\Delta S^{i}$, can be derived in a similar fashion. Let the expected permanent price impact asymmetry expression of stock $i$ at the opening of the market on day $t$ be defined as:

$$
J_{t}^{i}=E\left[\Delta B^{i} \mid \mathcal{F}_{t-1}, B^{i}\right]-E\left[\Delta S^{i} \mid \mathcal{F}_{t-1}, S^{i}\right]
$$

where $S^{i}$ in the conditioning information set represents a sell block trade. $J_{t}^{i}$ is positive, zero or negative if and only if the expected permanent price impact of buyer-initiated block trades is larger than, equal to or smaller than that of seller-initiated block trades, respectively.

Note that while the unconditional increase or decrease in the value of a stock over a day can be symmetric, the arrival of a block trade provides information and hence the resulting conditional distribution may be skewed in one direction or the other. The empirical literature investigating the price impact of blocks conditions on the execution of these trades and then looks at the changes in the proxies for equilibrium prices. Similarly, I condition on the arrival of a block trade and then ask what is the expected change in the value of the stock. If the magnitude of the expected change in value conditional on the arrival of a buy block is greater than that magnitude conditional on the arrival of a sell block (as documented by the empirical papers), the asymmetry expression will be positive.

Following Easley and O'Hara (1987), I define $\delta_{t}^{i}(B)$ as:

$$
\delta_{t}^{i}(B)=P\left(L^{i} \mid \mathcal{F}_{t-1}, B^{i}\right)+\delta^{i} P\left(O^{i} \mid \mathcal{F}_{t-1}, B^{i}\right)
$$

Hence, $\delta_{t}^{i}(B)$ is the probability that the true value of the stock reflects a loss on date $t$ conditional on the arrival of a block buy, whether or not information about the loss arrives 
in the market. $\delta_{t}^{i}(S)$ can be defined in a analogous manner. Plugging $\Delta B^{i}$ and $\Delta S^{i}$ into the permanent price impact asymmetry expression and using the definitions of $\delta_{t}^{i}(B)$ and $\delta_{t}^{i}(S)$ yields:

$$
J_{t}^{i}=2 \frac{Z_{t}^{i}}{V_{t-1}^{i}}\left[\delta^{i}-\delta_{t}^{i}(B)+\delta^{i}-\delta_{t}^{i}(S)\right]+2 r^{i}
$$

The asymmetry expression in (4) is comprised of two separate effects. The first term of the expression is the difference between the information content of buys and sells. $\left[\delta^{i}-\right.$ $\left.\delta_{t}^{i}(B)\right]$ can be thought of as a "distance" between the prior probability (for the day) and the posterior probability (conditional on observing a block buy) of a loss. The more (good) private information is associated with a buy, the smaller is $\delta_{t}^{i}(B)$, and the larger is the distance between the prior and the posterior. Similarly, $\left[\delta^{i}-\delta_{t}^{i}(S)\right]$ is the negative "distance" between the prior probability (for the day) and the posterior probability (conditional on observing a block sell) of a loss. The more (bad) private information is associated with a sell, the larger is $\delta_{t}^{i}(S)$, and the more negative is the distance between the prior and the posterior. Hence, heuristically, if buys contain more information than sells, the first "distance" dominates the term and the information effect gives rise to a positive asymmetry. If sells contain more information than buys, the second "distance" dominates the term and the information effect is negative.

The second term of expression (4) is the required return - the time value of money adjusted for risk. If investors expect a positive return on their investment, prices (cum dividend) will move up on average regardless of the trades that arrive in the market. This effect, however, can be small for short time intervals. Nonetheless, stocks with more systematic risk would ceteris paribus exhibit a larger permanent price impact asymmetry between buys and sells. Most empirical papers that documented the permanent price impact asymmetry controlled using various methods for the effect of the required return. Hence, the key to understanding the permanent price impact asymmetry lies in understanding the "information" term of $J_{t}^{i}$. 


\section{The Market}

\subsection{Institutional Investors}

There are four observations about the manner in which institutional investors behave that are central to modeling their dynamic trading strategy. While not all mutual funds behave according to them, many operate in a manner consistent with these observations. Hence, these observations can be viewed as describing a "prototypical" mutual fund. The first observation is that institutional investors devote substantial resources to the tasks of gathering and analyzing information. Portfolio managers make investment decisions based on predictions and recommendations produced by research departments. ${ }^{7}$ Also, it is no longer considered sufficient for analysts to determine the long-term prospects of firms. Reports in the popular press claim that predicting the short term movements of stocks is viewed as central to the analyst's job description. ${ }^{8}$ I model this observation by allowing institutions to invest in building a research infrastructure. This enables them to follow certain stocks that fit their preferred investment profile or that offer a cost advantage with respect to information gathering. Let $\mathcal{G}^{j}$ be the set of stocks followed by institutional investor $j$. For each stock $i$ in $\mathcal{G}^{j}$, the research department of the institution has determined that the cost of finding private information on the stock is not greater than the expected profit from knowing the private information. ${ }^{9}$

The second observation is that mutual funds primarily invest money received from shareholders. The Securities and Exchange Commission (SEC) limits the ability of mutual funds to use leverage. ${ }^{10}$ Even more importantly, many mutual funds place restrictions on using leverage in their charters. Reports in the popular press indicate that the investment style of mutual funds' portfolio managers is indeed shaped by these restrictions. ${ }^{11}$ The investment

\footnotetext{
${ }^{7}$ Mutual funds that do not have their own in-house research infrastructure pay substantial amounts in commissions to "sell side" institutions in exchange for research and analysis.

${ }^{8}$ See, for example, Joseph Nocera, "Who really moves the market?" Fortune Magazine, October 27, 1997.

${ }^{9}$ Each institutional investor may have its own cost advantage in different industries and so the set $\mathcal{G}^{j}$ depends on characteristics of the institutional investor that are not modeled explicitly.

${ }^{10}$ See Investment Company Act (1940) 80a-18 and Investment Company Act Release No. 7221 (1972).

${ }^{11}$ Bill Barnhart, "Investing in Mutual Funds," Chicago Tribune, July, 27, 1997.
} 
of limited sums of money creates the notion of an opportunity cost: money invested in one stock cannot be used to invest in another stock. To model this observation, each institutional investor is assumed to manage a portfolio with a certain number of stocks without the ability to borrow money in order to invest in more stocks. The number of stocks held by a mutual fund (and hence its size) can change due to trading profit, cash inflows and outflows, and dividends the mutual fund pays to its shareholders.

The third observation is that mutual funds hold relatively diversified portfolios consisting of many stocks. A mutual fund will not invest a large portion of its money in one stock, as such behavior will be hard to justify to shareholders (many of whom invest in mutual funds with the explicit objective of diversifying their holdings). Moreover, SEC rules that apply to most mutual funds limit the percentage holding of any one stock and hence de facto require diversification. ${ }^{12}$ In order to model the notion that mutual funds do not concentrate on only a few stocks and that the trades modeled here are large (i.e., block trades), I assume that a mutual fund's holding of a stock is equivalent to a block trade. This assumption will be referred to as the "diversification constraint." 13

The fourth observation is that most mutual funds hold stocks in non-negative amounts. ${ }^{14}$ Most mutual funds do not sell short as a matter of policy because it involves the risk of unlimited losses if the stock price goes up, and the charters of many mutual funds explicitly restrict the usage of short sales. ${ }^{15}$ Sharpe (1991) notes that some of this aversion is due to the implicit threat of suit for violation of fiduciary standards. The regulatory environment also takes part in discouraging short sales on the part of mutual funds. The SEC limits the amount of short sales a mutual fund can undertake (see Investment Company Act Release 7221 (1972)), and there are additional regulatory constraints on short selling (the up-tick rule)

\footnotetext{
${ }^{12}$ See Investment Company Act (1940) and Investment Company Act Release No. 7221 (1972).

${ }^{13}$ This constraint can be somewhat relaxed at the cost of additional complexity but without materially affecting the results. Institutional investors may hold multiple blocks of the same stock as long as they are increasingly averse to loading more of the same stock.

${ }^{14}$ See Falkenstein (1996).

${ }^{15}$ Randall Smith, "Big-block trading pits institutions, dealers in a fast, tough game," The Wall Street Journal, February 20, 1985.
} 
and on profit from short selling (the "short-short rule"). The end result is that institutions are looking for stocks to hold and not stocks to sell short. The restriction on short sales is imposed on mutual funds in this paper in a manner that resembles the true situation in the market. Unlike in Diamond and Verrecchia (1987), there is no fraction of sales that is arbitrarily assumed to be short sales. Instead, a mutual fund is prevented from selling a stock only when this stock is not in its portfolio. Hence, any inference on institutional trades will necessitate assessing the probability that a stock is in the portfolios of mutual funds. While a simple restriction on sells always creates an asymmetry, the true short sale constraint in this model allows for no asymmetry and even negative asymmetry (sells having a larger price impact than buys).

These four observations - the constant search for information, the investment of specific amounts, the holding of diversified portfolios, and the aversion to short selling - shape the optimal investment strategy of institutional investors. ${ }^{16}$ What should a mutual fund do in order to maximize expected profit? A simple buy and hold strategy will earn on average the required return on each stock. An uninformed dynamic strategy will do even worse (on average), since it involves transaction costs (e.g., the bid-ask spread) with no expected gain. Having the ability to search and trade on the basis of information, an institutional investor can hope to do better. Let $\mathcal{P}_{t}^{j}$ be the portfolio held by institutional investor $j$ at the beginning of day $t$ (before any re-balancing), and consider the following trading strategy:

Step 1 Search for information on all stocks in $\mathcal{P}_{t}^{j}$.

Step 2 Sell all stocks in $\mathcal{P}_{t}^{j}$ with bad information events.

Step 3 Search among stocks in $\mathcal{G}^{j} \backslash \mathcal{P}_{t}^{j}$ for stocks with good information events. Buy the stocks you find until you replace all the stocks sold and use whatever money that was carried

\footnotetext{
${ }^{16}$ One can wonder whether the emergence of hedge funds (that presumably face fewer constraints than mutual funds) has affected the information content of trades and the permanent price impact asymmetry. Since the amount of assets under mutual funds' management is much larger than the amount managed by hedge funds, it may be reasonable to conjecture that the trading strategies of mutual funds exert a larger influence on the information content of the order flow. Empirical work can be used to shed light on this issue.
} 
forward from previous days (if you exhaust all stocks in that set, hold money and skip Step 4).

Step 4 Continue to search in $\mathcal{G}^{j} \backslash \mathcal{P}_{t}^{j}$ for stocks with good information events. Upon finding such stocks, sell stocks in $\mathcal{P}_{t}^{j}$ with no information events and replace them with good information event stocks (continue until you replace all stocks with no information events in $\mathcal{P}_{t}^{j}$, or until you exhaust searching all stocks in $\mathcal{G}^{j} \backslash \mathcal{P}_{t}^{j}$, whichever comes first). ${ }^{17}$

The essence of this trading strategy is that portfolio managers rebalance their portfolios often to sell stocks that are viewed as going down or not moving anywhere and replace them with stocks on which they discover good information. ${ }^{18}$ This strategy is consistent with all four assumptions about the behavior of institutional investors, but is it profit maximizing? The answer to this question must depend on the cost of information in the economy and the manner in which market makers set prices. It is possible to derive a set of sufficient conditions for this trading strategy to be expected profit maximizing among all allowable trading strategies (where allowable strategies are those in which a mutual fund invests in a portfolio of stocks without borrowing or short selling). ${ }^{19}$ This set of sufficient conditions can be interpreted to characterize a world in which (i) information costs are not too high (i.e., the cost associated with searching for information on the gain or loss on any given date is low), (ii) the mutual funds' optimal search for stocks with good information events is not too lengthy (i.e., they do not spend too much money in the optimal search before finding

\footnotetext{
${ }^{17}$ This step is only carried out if there are good information event stocks in $\mathcal{G}^{j} \backslash \mathcal{P}_{t}^{j}$. Otherwise, it is never profitable to sell stocks with no information events since holding them earns the required return while replacing them entails trading costs (in the form of the bid-ask spread) while the newly purchased stocks can also earn at most the required return.

${ }^{18}$ The popular press attributes the high turnover of stocks in the portfolios of mutual funds to the constant search for "winning" stocks (see Michael Blumstein, "How the Institutions Rule the Market," The New York Times, November 25, 1984). The average turnover rate of stocks in the portfolios of mutual funds in 1996 was 91 percent (Jane Bryant Quinn, "Trading Away the Strength of Mutual Funds," The Washington Post, September, 28, 1997).

${ }^{19} \mathrm{~A}$ derivation of these sufficient conditions appeared in a previous version of this paper. The derivation assumes that institutions use their experience to perform an optimal search among the stocks in $\mathcal{G}^{j}$ and that prices are set by risk neutral and competitive market makers. The assumptions on the behavior of the market makers are similar to those in Glosten and Milgrom (1985) and Easley and O'Hara (1987, 1992).
} 
a good stock), and (iii) information is not impounded into prices too quickly (i.e., there is enough uninformed trading). The first two conditions constitute a requirement on the research technology of institutions whereby the process of finding stocks in which to invest is not too costly. The last condition is a requirement on the trading environment: without a sufficient number of uninformed investors, spreads will be very wide (see also Glosten and Milgrom (1985)) and therefore transactions costs will make this dynamic trading strategy unprofitable.

The first observation about the behavior of mutual funds is that they constantly search for information about stocks. This behavior would not make sense if information costs or the costs of the optimal search in the real world were too great. Hence, I will assume in the rest of the paper that institutional investors in the market follow this trading strategy. ${ }^{20}$ Note that this trading strategy implicitly assumes that institutional investors would rather hold cash than buy stocks on which they have no information. Another implicit assumption is that mutual funds can always meet redemption needs by selling stocks that experience either bad information or no information events. In other words, they will not sell stocks on which they discover good information. If mutual funds in the real world behave sometimes in a manner that violates these assumptions, the trading strategy described here can be viewed as an approximation of the one actually employed by mutual funds. Controlling for noise that may be introduced by these implicit assumptions is important for empirical tests of the model. This point is further discussed in Section 3.2. In the spirit of the quote from Chan and Lakonishok (1993), I will also make the simplifying assumption that the number of stocks about which a mutual fund can collect information (i.e., the cardinality of $\mathcal{G}^{j}$ ) is large relative to the number of stocks in the mutual fund's portfolio. Hence, there will be enough stocks with good information events in the universe of stocks followed by a mutual fund to replace all stocks with bad information and no information events in its portfolio.

\footnotetext{
${ }^{20}$ Transactions costs (beyond the information-asymmetry-driven bid-ask spread that is determined endogenously) could make Step 4 of the trading strategy (selling stocks that are not moving to buy stocks that will go up) less profitable. It can be shown that if mutual funds carry out only steps 1 through 3 of the trading strategy, the results in Section 3.1 remain intact though the magnitude of the effects may be smaller.
} 
This assumption is not necessary for deriving the results in Section 3.1, but it simplifies the presentation considerably.

\subsection{Uninformed Traders}

The economy is also populated by uninformed traders. They are called uninformed since they do not know the realization of the gain or loss of a firm during the trading day, but rather discover it when the information is publicly revealed at night. The identity of the uninformed traders is by default all traders who are not information-intensive institutional investors. Some institutional investors in the real world, like index funds, fit the characterization of uninformed traders. Individuals and portfolio managers who believe they have real information but in fact trade on pure noise satisfy the description of uninformed traders as well. If inflows or outflows of money create a situation in which portfolio managers of mutual funds feel they have to buy or sell stocks without the support of research, these transactions will be part of the uninformed order flow. ${ }^{21}$ This paper does not differentiate buys from sells on non-informational (e.g., liquidity) grounds. Hence, uninformed traders are assumed to buy or sell with equal probabilities.

For the sake of parsimony, I model only uninformed block trading. The model can be easily extended to include small uninformed trades. ${ }^{22}$ This extension produces practically identical results to those presented here. Easley and O'Hara (1987) use a sequential trade model with two sizes of trades to investigate whether informed traders will use both small and large trades. They show that if a large trade is "large enough" relative to a small trade, a separating equilibrium prevails in which the informed traders use only large trades. Since block trades are indeed much larger than small trades, it is reasonable to assume the existence of such a separating equilibrium in the market modeled here as well. ${ }^{23}$ Hence, I

\footnotetext{
${ }^{21}$ The trading strategy of institutional investors in Section 2.1 can therefore be viewed as describing only a part of the trading strategy of an institution - the part that is based on information.

${ }^{22}$ The parameters of such an extension can then be set to reflect the fact that block trades are indeed not as common as small trades.

${ }^{23}$ The equilibrium condition used by Easley and O'Hara to generate their result is simply that the profit of an informed trader from using a large trade (i.e., the number of shares times the difference between the
} 
abstract from the issue of small trades and focus on the interaction in the market for blocks.

Also for parsimony, the arrival of uninformed traders to the market is assumed rather than derived from a larger set of investment strategies. Note, however, that if we let uninformed investors choose between investing through mutual funds and arriving to the market separately, they will arrive to the market only if they are indifferent between these two strategies. Therefore, any profit made by mutual funds as a result of trading on information (beyond the required return) should be exhausted by the cost of maintaining the research infrastructure and searching for information. ${ }^{24}$ Uninformed investors who choose to invest through mutual funds would ultimately bare the cost of the information gathering activity as part of the management fees and hence would not be making excess returns. ${ }^{25}$ Therefore, the existence of uninformed traders in the market alongside informed mutual funds can be consistent with a more elaborate model in which the investment strategy of the uninformed traders is endogenized.

\subsection{The Trading Model}

Every day is divided into $L$ trading periods. Each period allows for at most one trade. Most stock exchanges in the world have a mechanism and a set of procedures that facilitate the execution of individual orders. This mechanism can take the form of a specialist (NYSE), multiple dealers (NASDAQ), an electronic limit order book (the Paris Bourse), and so on. Since the permanent price impact of a trade is not affected by the actual price paid for the

transaction price and the equilibrium value of the stock) is greater than her profit from using a small trade. Setting up the appropriate equilibrium condition in my model is more involved since an institution's profit depends on its entire trading strategy (that includes buying, holding, and selling the stock depending on the information events and the portfolio position). Nonetheless, the equilibrium condition is influenced by the same forces as in the Easley and O'Hara model (basically the number of shares in a trade versus the price impact of the trade) and hence a similar intuition should generate the separating equilibrium.

${ }^{24} \mathrm{~A}$ previous version of this paper presented an equilibrium condition where the expected trading profit of an institutional investor was set equal to the expected information gathering costs. For some recent evidence of this "competitive market for information" see John Waggoner, "Mutual Funds Bid Up Pay of Senior Stock Analysts," USA Today, February 11, 1997; Charles Gasparino, "Mutual Funds Show Managers The Money, Seeking Big Returns," Wall Street Journal, March 7, 1997.

${ }^{25}$ This property ties into the extensive literature on the performance of mutual funds. While some papers find that mutual funds trade as if they have information, it does not appear that they can deliver better performance than some benchmarks, especially after management costs are taken into consideration. For a recent review of this literature see Grinblatt and Titman (1995). 
shares, I need not be specific about the manner in which prices are set in this economy. The only assumption I am making is that trading is anonymous: observing an order does not reveal to the market the identity of the trader (i.e., whether it comes from an informed institutional investor or an uninformed trader). Hence, the market cannot separate institutional investors from uninformed traders and has to resort to probabilistic inference on the information content of any particular order.

The probability that an institutional investor that follows stock $i$ arrives in the market at any period during the day is given by $\nu^{i}$. Since each trading period can accommodate only one trader, the probability that an uninformed investor arrives to the market is $1-\nu^{i}$. If a mutual fund that follows stock $i$ arrives in the market on date $t$, the probability that it will buy or sell stock $i$ depends on the nature of the information event about the stock and whether the stock is in the mutual fund's portfolio. When the stock is in its portfolio and a good information event takes place, the mutual fund cannot load more of the stock due to the diversification constraint. If bad information or no information events occur, the mutual fund can sell the stock since the short sale constraint is not binding. When the stock is not in its portfolio and bad information or no information events occur, the mutual fund cannot sell the stock since the short sale constraint is binding. If a good information event takes place, the mutual fund can buy the stock since the diversification constraint is not binding. Whether the mutual fund in fact buys the stock depends on whether it searched for information on that particular stock on that day. A priori, therefore, the diversification constraint works to limit informed buys and the short sale constraint works to limit informed sells. The degree to which these constraints are expected to bind the trading of informed institutional investors is the key to understanding the price impact asymmetry of trades.

Define $\Omega_{t}^{i} \in[0,1)$ to be the market's assessment of the probability that a mutual fund will search for information about stock $i$ on date $t$ if the stock had a good information event day and is not in the mutual fund's portfolio. ${ }^{26}$ Denote the probability that a stock is in the

\footnotetext{
${ }^{26} \Omega_{t}^{i}$ is strictly less than one since it is possible that all stocks in the portfolio of an institution will have good information events, in which case the institution will not search for information on any additional stock.
} 
portfolio of an institutional investor by $\gamma_{t, q}^{i}$. The subscript $q$ (for stock $i$ on date $t$ ) is the length of the current run of good information event days that is known to the market, or the number of consecutive days in which stock $i$ had good information events up to date $t-1$. For example, $q=0$ means that there was either a bad information event or a no information event on date $t-1$. Given the trading strategy of mutual funds, stock $i$ cannot be in the portfolio of a mutual fund on date $t$ since it would have been sold at $t-1$ if it was in the portfolio then and would not have been bought otherwise. Hence, to calculate the probability that stock $i$ is in the portfolio of a mutual fund on date $t$ we need not consider the entire history of information events, but rather only what has happened from the beginning of the current run of good information events.

Since a mutual fund will buy a stock only once during any given run of good information events (due to the diversification constraint), and will not sell that stock until the run ends, the probability that stock $i$ is in the portfolio of a mutual fund that arrives in the market equals the probability that stock $i$ was bought by the mutual fund in all previous days during the current run. More specifically,

$$
\begin{aligned}
\gamma_{t, 0}^{i} & =0 \\
\gamma_{t, 1}^{i} & =\Omega_{t-1}^{i}\left(1-\gamma_{t-1,0}^{i}\right)=\Omega_{t-1}^{i} \\
\gamma_{t, 2}^{i} & =\Omega_{t-2}^{i}\left(1-\gamma_{t-2,0}^{i}\right)+\Omega_{t-1}^{i}\left(1-\gamma_{t-1,1}^{i}\right)=\Omega_{t-1}^{i}+\Omega_{t-2}^{i}\left(1-\Omega_{t-1}^{i}\right) \\
\vdots & \vdots \\
\gamma_{t, q}^{i} & =\sum_{p=1}^{q} \Omega_{t-p}^{i}\left(1-\gamma_{t-p, q-p}^{i}\right)
\end{aligned}
$$

Fixing $t, \gamma_{t, q}^{i}$ is increasing in $q$ (since we are adding non-negative terms to the expression).

The trading probabilities and the associated trading outcomes are depicted in Figure 1. On a bad information event day, an institutional investor will sell a block with probability $\gamma_{t, q}^{i}$. With probability $1-\gamma_{t, q}^{i}$, the stock is not in its portfolio and so the short sale constraint is binding and the institution does not trade in stock $i$. On a good information event day, an institutional investor will buy if the stock is not in its portfolio and if it searched for information on the stock. Since these events are independent (due to the independence of information events across days), the institution will therefore buy a block with probability $\Omega_{t}^{i}\left(1-\gamma_{t, q}^{i}\right)$. Otherwise, it does not trade in stock $i$. On a no information event day, an 
institutional investor sells if the stock is in its portfolio (with probability $\gamma_{t, q}^{i}$ ) and otherwise does not trade in stock $i$.

\section{Properties of the Price Impact Asymmetry}

The expected permanent price impact asymmetry expression in (4) can be generalized to apply to each of the $l \leq L$ periods in a day by adding the sequence of trades from the beginning of the day to the conditioning information set. Let $Q^{l}$ be the sequence of realized trading outcomes up to and including period $l$. The generalized asymmetry expression for period $l+1$ will be:

$$
\hat{J}_{t, l+1}^{i}=2 \frac{Z_{t}^{i}}{V_{t-1}^{i}}\left[\delta^{i}-\delta_{t}^{i}\left(Q^{l}, B\right)+\delta^{i}-\delta_{t}^{i}\left(Q^{l}, S\right)\right]+2 r^{i}
$$

where the market uses Bayes rule to calculate $\delta_{t}^{i}\left(Q^{l}, B\right)$ and $\delta_{t}^{i}\left(Q^{l}, S\right) .{ }^{27}$ Given any arbitrary history of trading outcomes $Q^{l}$, the arrival of a block trade in period $l+1$ causes the market to update its expectation of the percentage change in the equilibrium value of the stock (i.e., today's true value relative to yesterday's true value). The revision in expectations reflects the information content of the block and results in a permanent price impact. Plugging the probabilities from the trading model into expression (5), the asymmetry expression becomes:

$$
\begin{aligned}
\hat{J}_{t,(b, s, n)}^{i}= & 2 r^{i}+2 \frac{Z_{t}^{i}}{V_{t-1}^{i}} \alpha^{i} \delta^{i}\left(1-\delta^{i}\right) \cdot \\
& {\left[\frac{\left[1+\frac{2 \nu^{i} \Omega_{t}^{i}\left(1-\gamma_{t, q}^{i}\right)}{1-\nu^{i}}\right]^{b+1}\left[\frac{\left.1-\nu^{i}\right)}{2 \nu^{i} \gamma_{t, q}^{i}+1-\nu^{i}}\right]^{s}\left[\frac{1-\Omega_{t}^{i}\left(1-\gamma_{t, q}^{i}\right)}{1-\gamma_{t, q}^{i}}\right]^{n}-1}{1-\alpha^{i}\left(1-\delta^{i}\right)+\alpha^{i}\left(1-\delta^{i}\right)\left[1+\frac{2 \nu^{i} \Omega_{t}^{i}\left(1-\gamma_{t, q}^{i}\right)}{1-\nu^{i}}\right]^{b+1}\left[\frac{\left.1-\nu^{i}\right)}{2 \nu^{i} \gamma_{t, q}^{i}+1-\nu^{i}}\right]^{s}\left[\frac{1-\Omega_{t}^{i}\left(1-\gamma_{t, q}^{i}\right)}{1-\gamma_{t, q}^{i}}\right]^{n}}\right.} \\
& \left.+\frac{\left[1+\frac{2 \nu^{i} \Omega_{t}^{i}\left(1-\gamma_{t, q}^{i}\right)}{1-\nu^{i}}\right]^{b}\left[\frac{\left.1-\nu^{i}\right)}{2 \nu^{i} \gamma_{t, q}^{i}+1-\nu^{i}}\right]^{s+1}\left[\frac{1-\Omega_{t}^{i}\left(1-\gamma_{t, q}^{i}\right)}{1-\gamma_{t, q}^{i}}\right]^{n}-1}{1-\alpha^{i}\left(1-\delta^{i}\right)+\alpha^{i}\left(1-\delta^{i}\right)\left[1+\frac{2 \nu^{i} \Omega_{t}^{i}\left(1-\gamma_{t, q}^{i}\right)}{1-\nu^{i}}\right]^{b}\left[\frac{\left.1-\nu^{i}\right)}{2 \nu^{i} \gamma_{t, q}^{i}+1-\nu^{i}}\right]^{s+1}\left[\frac{1-\Omega_{t}^{i}\left(1-\gamma_{t, q}^{i}\right)}{1-\gamma_{t, q}^{i}}\right]^{n}}\right]
\end{aligned}
$$

\footnotetext{
$\delta_{t}^{i}\left(Q^{l}, B\right)$ and $\delta_{t}^{i}\left(Q^{l}, S\right)$ as follows:

$$
\begin{aligned}
\delta_{t}^{i}\left(Q^{l}, B\right) & =\delta^{i} \frac{\prod_{s=1}^{l} P\left(Q_{s} \mid \psi_{t}^{i}=L\right) P\left(B \mid \psi_{t}^{i}=L\right)}{\sum_{\psi_{t}^{i}} P\left(\psi_{t}^{i}\right) \prod_{s=1}^{l} P\left(Q_{s} \mid \psi_{t}^{i}\right) P\left(B \mid \psi_{t}^{i}\right)} \\
\delta_{t}^{i}\left(Q^{l}, S\right) & =\delta^{i} \frac{\prod_{s=1}^{l} P\left(Q_{s} \mid \psi_{t}^{i}=L\right) P\left(S \mid \psi_{t}^{i}=L\right)}{\sum_{\psi_{t}^{i}} P\left(\psi_{t}^{i}\right) \prod_{s=1}^{l} P\left(Q_{s} \mid \psi_{t}^{i}\right) P\left(S \mid \psi_{t}^{i}\right)}
\end{aligned}
$$
}

${ }^{27}$ Let $\psi_{t}^{i}$ be the information event on day $t$, and $Q_{s}$ be the trading outcome in period $s \leq l$. Then, one can use the independence of trade arrival when conditioning on the type of information event and the similarity in the trading strategies of institutions on no information event and bad information event days to write 
where $b, s$, and $n$ are the number of buy blocks, sell blocks, and no trade outcomes in $Q^{l}$, respectively. ${ }^{28}$

The discussion in Section 2.3 emphasizes how the asymmetry in the information content of trades is driven by differences in the portfolio positions of institutional investors across days. Hence, different intra-day realizations of the vector $(b, s, n)$ are of secondary importance. In other words, to investigate the influence of institutional investors we should fix a vector $(\bar{b}, \bar{s}, \bar{n})$, and look at how differences in $\gamma_{t, q}^{i}$ affect the asymmetry and how they interact with the other parameters of the model. For simplicity, I fix the vector at $(0,0,0)$ and examine the price impact asymmetry expression after the opening of the market every day. Plugging $(0,0,0)$ into expression (6) yields: ${ }^{29}$

$$
\begin{aligned}
J_{t}^{i}= & 2 \frac{Z_{t}^{i}}{V_{t-1}^{i}} \alpha^{i} \delta^{i}\left(1-\delta^{i}\right) \nu^{i}\left[\frac{\Omega^{i}\left(1-\gamma_{t, q}^{i}\right)}{\alpha^{i}\left(1-\delta^{i}\right) \nu^{i} \Omega_{t}^{i}\left(1-\gamma_{t, q}^{i}\right)+\frac{1}{2}\left(1-\nu^{i}\right)}\right. \\
& \left.-\frac{\gamma_{t, q}^{i}}{\left[1-\alpha^{i}\left(1-\delta^{i}\right)\right] \nu^{i} \gamma_{t, q}^{i}+\frac{1}{2}\left(1-\nu^{i}\right)}\right]+2 r^{i}
\end{aligned}
$$

The above expression can now be used to analyze the relation between the expected permanent price impact asymmetry and the economic environment.

\subsection{Results}

The first two results focus on the major importance of conditioning on past price performance of a stock in understanding the expected permanent price impact asymmetry.

Result 1 The asymmetry expression of a stock that did not experience a signi cant price appreciation in the previous day is always strictly positive.

\footnotetext{
${ }^{28}$ This form of the expression is valid for any finite $q$ (i.e., $\gamma_{t, q}^{i} \neq 1$ ). written as:

$$
\begin{aligned}
& \delta_{t}^{i}(B)=\delta^{i}\left[\frac{\frac{1}{2}\left(1-\nu^{i}\right)}{\alpha^{i}\left(1-\delta^{i}\right) \nu^{i} \Omega_{t}^{i}\left(1-\gamma_{t, q}^{i}\right)+\frac{1}{2}\left(1-\nu^{i}\right)}\right] \\
& \delta_{t}^{i}(S)=\delta^{i}\left[\frac{\nu^{i} \gamma_{t, q}^{i}+\frac{1}{2}\left(1-\nu^{i}\right)}{\left[1-\alpha^{i}\left(1-\delta^{i}\right)\right] \nu^{i} \gamma_{t, q}^{i}+\frac{1}{2}\left(1-\nu^{i}\right)}\right]
\end{aligned}
$$
}

${ }^{29}$ One can go directly from (4) to $(7)$ by noting that $\delta_{t}^{i}(B)$ and $\delta_{t}^{i}(S)$ at the opening of the market can be 
Result 2 The longer the run of price appreciations a stock experiences (the larger q), the smaller is the price impact asymmetry expression.

Proofs of all the results in this section can be found in the Appendix. For low $q$ (and especially for $q=0$ ), the probability that any institutional investor owns a block of the stock is low. Hence, it is unlikely that the diversification constraint is binding on a "typical" mutual fund that follows stock $i$, but the short sale constraint is most likely binding. In this case, good information about the stock may prompt many mutual funds to buy it, resulting in a high probability of an informed buy. Since most mutual funds do not own the stock, they cannot sell it on a bad information event day, and hence the probability of an informed sell is low. This creates a positive permanent price impact asymmetry.

As $q$ increases and the stock price goes up, more mutual funds buy the stock. After a long period of abnormal price appreciation (above and beyond the required return), which is equivalent to saying that $q$ is large, the probability that a stock is in an institutional portfolio is also high. A mutual fund that has the stock in its portfolio will not buy more blocks of the same stock and hence the probability of an informed buy decreases. On the other hand, since many mutual funds own the stock, the short sell constraint is not binding and bad information will result in informed sells. Hence, the probability of an informed sell increases. This effect makes the asymmetry expression less and less positive. If the stock price has been going up for a sufficiently long period, we may even see a negative asymmetry expression. Still, the probability of a large $q$ is very small and hence the implications of the model are consistent with the empirical findings of positive asymmetry. For example, a stock with $\alpha^{i}=0.5$ and $\delta^{i}=0.35$ will have $q=0$ with probability $0.675, q=1$ with probability $0.219, q=2$ with probability 0.071 , and $q \geq 3$ with probability of only 0.034 . Whether $J_{t}^{i}$ will be positive or negative for $q \geq 1$ depends on the values of the parameters of the stock.

Results 1 and 2 imply that stocks which generate more and shorter runs (e.g., with $\left.\alpha^{i}\left(1-\delta^{i}\right) \approx \frac{1}{2}\right)$ will have on average more days with low $q$, and hence will more often exhibit a large permanent price impact asymmetry. Note, however, that $q$ is always known. 
Hence, analyzing the influence of the other fundamentals of the economy on the asymmetry expression will be done taking $q$ as given and conditioning on a stock being at a particular point in the run of good information events.

Result 3 When a stock's price has not been rising or is at the beginning of a good run, the greater the trading intensity of institutional investors (the larger $\nu^{i}$ ), the larger is the asymmetry expression. For su ciently large $q$, the greater the trading intensity of institutional investors, the smaller is the price impact asymmetry expression.

What affects the price impact asymmetry most at the beginning of a good run is the probability of an informed buy. The greater the trading intensity of institutional investors, the more informed buy orders will arrive in the market, and hence the larger the price impact asymmetry. As the number of consecutive price appreciations increases, the probability that the stock is in an institutional portfolio increases as well. When the good run ends, having more institutional trading means more informed sells. Hence, the larger $\nu^{i}$, the less positive is the price impact asymmetry expression for a large enough $q$.

Result 4 When a stock's price has not been rising or is at the beginning of a good run, the more informationally-active a stock (the higher $\alpha^{i}$ ), the larger is the asymmetry expression. For su ciently large $q$, the more informationally-active a stock, the smaller is the price impact asymmetry expression.

The more information events, the higher the probability that there was a good information event and so it is more likely that a buy is informed. At the same time, the probability of bad information events increases as well. For low $q$, the increase in the probability of an informed buy is larger than the increase in the probability of an informed sell (especially for $q=0$ when sells cannot be informed). For very large $q$, the opposite result occurs since sells are more likely to be informed than buys. ${ }^{30}$

\footnotetext{
${ }^{30}$ The parameter $\delta^{i}$ affects both the distribution of good and bad information events and the magnitude of the price impact of blocks. For example, an increase in the probability of a bad information event
} 
Result 5 When a stock's price has not been rising or is at the beginning of a good run, the greater the stock's price dispersion, the larger is the asymmetry expression. For su ciently large $q$, the greater the stock's price dispersion, the smaller is the asymmetry expression.

In general, a block trade will have a larger price impact the greater the dispersion of the value process of a stock. If the information term of the asymmetry expression is positive, greater dispersion will make the asymmetry even more positive. If, due to being far into the run of good information events, the information term of the asymmetry expression is negative, greater dispersion will make the asymmetry expression less positive by increasing the influence of the negative information term.

\subsection{Discussion of the Empirical Implications}

The advantage of looking at the behavior of institutional investors to explain the permanent price impact asymmetry lies in the additional insights that come out of the model. While the model indeed shows how a positive asymmetry expression can arise, it goes further to detail the influence of elements in the economic environment on the asymmetry. Testing the model is therefore equivalent to testing these additional implications. In fact, the ability of the model to produce no asymmetry and even negative asymmetry in certain circumstances can be very important in constructing further investigations of this phenomenon.

The main insight that comes out of the model is the relation between the history of price performance and the expected permanent price impact asymmetry. Block trades during periods of poor price performance or little price appreciation should exhibit stronger positive asymmetry. Block trades that come after a long price run-up should exhibit less asymmetry

$\left(\delta^{i}\right)$ is accompanied by a decrease in the magnitude of the price impact on a bad information event day $\left(2\left(1-\delta^{i}\right) \frac{Z_{t}^{i}}{V_{t-1}^{i}}\right)$. Since the expected price impact asymmetry is the sum of probabilities multiplied by changes in value, we would expect to have a non-monotone relationship between the expected permanent price impact asymmetry and $\delta^{i}$ even after conditioning on $q$. For example, it can be shown that when $q=0$, there is a unique value of $\delta^{i}$ that is strictly between zero and one that maximizes the asymmetry expression. On the other hand, when $q$ is very large and the entire asymmetry expression is negative, maximizing it is equivalent to eliminating uncertainty in the economy by setting $\delta^{i}$ to either zero or one. For any intermediate $q$, the value of $\delta^{i}$ that maximizes the expression depends on the other parameters of the stock. 
or even negative asymmetry. Note that testing this prediction requires one to specify the length of the period over which price performance is measured.

To make the model more parsimonious, I use a single time interval — a "day" — for three different purposes. First, it is the interval between the pre and post-equilibrium prices that are used to evaluate the price impact of blocks. Second, it is the horizon for creation and revelation of private information. Third, it is the period over which institutional investors rebalance their portfolios. The model, however, can be used to derive asymmetry expressions for many different specifications of the equilibrium prices (e.g., the prices of the trades before and after the block transaction). The ability to accomodate (though at the cost of additional complexity) separate periods for the measurement of price impact and the creation of information (or portfolio re-balancing) provides some flexibility to the empirical analysis. For example, the length of time over which to measure the asymmetry can be one day, but it can also be shorter (a few trades before and after the block) if one believes that prices in the market adjust very quickly to the information content of blocks. On the other hand, the period over which an information event takes place or an institutional investor re-balances its portfolio may in fact be longer than a day (or even a month).

Another important issue is the choice of trades to represent the blocks analyzed in the model. Since the model identifies the cause of the asymmetry with institutional behavior, one can adopt the view that all institutional trades should exhibit this asymmetry. Including medium-size trades in the analysis (usually defined as 1,000-10,000 shares) may increase the sample size considerably. However, including medium-size trades in the sample may increase the noise as smaller trades may be motivated by various reasons not considered in the theoretical analysis. Since previous empirical studies concluded that larger trades contain more private information than smaller trades (Seppi, 1992; Madhavan and Cheng, 1997; Lynch Koski and Michaely, 1997), an alternative approach would be to limit the analysis to larger trades (blocks) in an attempt to reduce the noise. ${ }^{31}$ Whichever approach one takes,

\footnotetext{
${ }^{31}$ The findings of Lightfoot, Martin, Peterson, and Sirri (1997) using order data (rather than trade data) also suggest that the information content of orders is monotonically increasing with size.
} 
it may be worthwhile to exclude very large blocks from the analysis. Since very large blocks are usually traded in the upstairs market (where there is much less anonymity and the issue of reputation may be important), they may behave differently than the blocks modeled in this paper.

The model identifies several parameters of the environment that should influence the asymmetry. While the trading intensity of institutional investors should affect the asymmetry, identifying proxies for informed institutional investors may be far from trivial. The number of institutional shareholders or the percentage holdings of a stock by institutions can be very misleading proxies as they can hide many uninformed institutions (e.g., index funds). It may be possible to identify $\nu^{i}$, as well as the other parameters of the model, without resorting to data beyond that contained in the sequence of trades. Easley, Kiefer and O'Hara (1997a, 1997b) have developed a maximum likelihood estimation technique that imposes similar structural trade models on signed trade data (buy and sell orders). The parameters are identified solely on the basis of their implications vis-a-vis the trading process. One clear advantage of this methodology is that no external proxies are being used. However, if blocks do not trade frequently enough, estimation of the parameters using block data alone may not be very precise.

Designing appropriate controls for the empirical analysis becomes an important issue if mutual funds in the real world trade for various reasons not accounted for in the model. One such reason may be the volatile flow of money into and out of funds (see Chevalier and Ellison (1997); Del Guercio and Tkac (1998)). In the model, I assume that managers can always search for information on stocks and find enough stocks with good information events (or hold money). What if the inflow is so great as to overwhelm the research capabilities of an institution, but portfolio managers still feel they must invest to show that they are doing their job? What if the outflow is so severe that it requires selling stocks on which the institutional investor discovers good information? Borrowing constraints will make the influence of flows on the portfolios of mutual funds even more pronounced. Since empirical tests of the model 
should focus on the information-based part of the trading strategy of institutional investors, controlling for inflows and outflows could help the investigation considerably. ${ }^{32}$ In addition, it may be necessary to control for events that trigger intensive uninformed block trading with a predominant direction. For example, changes to the composition of the S\&P500 index generate abnormal uninformed block trading by index funds. Excluding such events from the analysis can reduce noise and strengthen the link between abnormal block trading and the existence of private information. ${ }^{33}$

\section{Conclusion}

The existence of a permanent price impact asymmetry between buyer and seller-initiated block transactions (and institutional trades) has been documented in the empirical literature in finance. This paper contributes to this literature by developing a theoretical model to explain and investigate the asymmetry phenomenon. The model is based on the premise that the profit maximizing behavior of institutional investors creates a difference between the information content of buys and sells. There are two driving forces behind the asymmetry phenomenon. The first is the manner in which portfolio managers optimally use information when they have the ability to search for private information about multiple stocks. The second is a set of constraints on the allowable trading strategies of portfolio managers. Incorporating the dynamic trading strategy of mutual funds in a simple trading model allows for the explicit derivation and investigation of the expected permanent price impact asymmetry.

A central implication of the model is that the history of price performance influences the asymmetry. The longer the (abnormal) run-up in a stock's price, the less is the asymmetry. In fact, the model predicts no asymmetry or even negative asymmetry following very long price run-ups. The greater the trading intensity of institutional investors, the more pronounced is the asymmetry when the stock's price has not been going up. The opposite result appears

\footnotetext{
${ }^{32}$ For a discussion of this point see Edelen (1998).

${ }^{33}$ Alternatively, one can use such events as an additional test of the model since block sells that are associated with a deletion from the index and block buys that are associated with an addition to the index need not exhibit the permanent price impact asymmetry.
} 
after a long period of price appreciation. Similarly, the more "informationally-active" a stock, the greater is the asymmetry if the stock's price has not been going up or is at the beginning of a series of price appreciations. The opposite result appears after a long price run-up. Greater dispersion of a stock's price affects the asymmetry by increasing the influence of the informational effect. It is hoped that the framework developed in this paper can aid researchers who are planning empirical investigations of the asymmetry phenomenon or the effects of institutional investors on financial markets in general. 


\section{Appendix}

Proof of Result 1: If the stock's price did not go up substantially in the previous day, it must be that the previous day was either a bad information or a no information event day. Hence, $q=0$ which implies $\gamma_{t, q}^{i}=0$.

$$
\left.J_{t}^{i}\right|_{q=0}=2 \frac{Z_{t}^{i}}{V_{t-1}^{i}} \alpha^{i} \delta^{i}\left(1-\delta^{i}\right) \nu^{i} \frac{\Omega_{t}^{i}}{\alpha^{i}\left(1-\delta^{i}\right) \nu^{i} \Omega_{t}^{i}+\frac{1}{2}\left(1-\nu^{i}\right)}+2 r^{i}>0
$$

Q.E.D

Proof of Result 2: Note that the only parameter affected by $q$ is $\gamma_{t, q}^{i}$, which is monotonically increasing in $q$. Hence, it suffices to show that $J_{t}^{i}$ is decreasing in $\gamma_{t, q}^{i}$.

$$
\begin{aligned}
\frac{\partial J_{t}^{i}}{\partial \gamma_{t, q}^{i}}= & 2 \frac{Z_{t}^{i}}{V_{t-1}^{i}} \alpha^{i} \delta^{i}\left(1-\delta^{i}\right) \nu^{i}\left[\frac{-\frac{1}{2} \Omega_{t}^{i}\left(1-\gamma_{t, q}^{i}\right)}{\left[\alpha^{i}\left(1-\delta^{i}\right) \nu^{i} \Omega_{t}^{i}\left(1-\gamma_{t, q}^{i}\right)+\frac{1}{2}\left(1-\nu^{i}\right)\right]^{2}}\right. \\
& \left.-\frac{\frac{1}{2}\left(1-\nu^{i}\right)}{\left[\left[1-\alpha^{i}\left(1-\delta^{i}\right)\right] \nu^{i} \gamma_{t, q}^{i}+\frac{1}{2}\left(1-\nu^{i}\right)\right]^{2}}\right]<0
\end{aligned}
$$

Q.E.D

\section{Proof of Result 3:}

$$
\begin{aligned}
\frac{\partial J_{t}^{i}}{\partial \nu^{i}}= & \frac{Z_{t}^{i}}{V_{t-1}^{i}}\left[\frac{\Omega_{t}^{i}\left(1-\gamma_{t, q}^{i}\right)}{\left[\alpha^{i}\left(1-\delta^{i}\right) \nu^{i} \Omega_{t}^{i}\left(1-\gamma_{t, q}^{i}\right)+\frac{1}{2}\left(1-\nu^{i}\right)\right]^{2}}\right. \\
& \left.-\frac{\gamma_{t, q}^{i}}{\left[\left[1-\alpha^{i}\left(1-\delta^{i}\right)\right] \nu^{i} \gamma_{t, q}^{i}+\frac{1}{2}\left(1-\nu^{i}\right)\right]^{2}}\right]
\end{aligned}
$$

For $q=0$,

$$
\left.\frac{\partial J_{t}^{i}}{\partial \nu^{i}}\right|_{q=0}=\frac{Z_{t}^{i}}{V_{t-1}^{i}} \frac{\Omega_{t}^{i}}{\left[\alpha^{i}\left(1-\delta^{i}\right) \nu^{i} \Omega_{t}^{i}+\frac{1}{2}\left(1-\nu^{i}\right)\right]^{2}}>0
$$

For $q \geq 1$, the sign depends on the values of the other parameters. As $q$ increases, the second term of (8) begins to dominate and the expression becomes negative. In particular, we can use infinity as an approximation for a large $q$ to show that the expression will become negative for all values of the other parameters (note that $\gamma_{t, q}^{i}$ approaches one as $q$ approaches infinity as all institutions have already bought the stock after an infinite number of good information event days).

$$
\lim _{q \rightarrow \infty} \frac{\partial J_{t}^{i}}{\partial \nu^{i}}=-\frac{Z_{t}^{i}}{V_{t-1}^{i}} \frac{1}{\left[\left[1-\alpha^{i}\left(1-\delta^{i}\right)\right] \nu^{i}+\frac{1}{2}\left(1-\nu^{i}\right)\right]^{2}}<0
$$

Q.E.D 


\section{Proof of Result 4:}

$$
\begin{aligned}
\frac{\partial J_{t}^{i}}{\partial \alpha^{i}}= & 2 \frac{Z_{t}^{i}}{V_{t-1}^{i}} \delta^{i}\left(1-\delta^{i}\right) \nu^{i}\left[\frac{\frac{1}{2}\left(1-\nu^{i}\right) \Omega_{t}^{i}\left(1-\gamma_{t, q}^{i}\right)}{\left[\alpha^{i}\left(1-\delta^{i}\right) \nu^{i} \Omega_{t}^{i}\left(1-\gamma_{t, q}^{i}\right)+\frac{1}{2}\left(1-\nu^{i}\right)\right]^{2}}\right. \\
& \left.-\frac{\left(\gamma_{t, q}^{i}\right)^{2} \nu^{i}+\frac{1}{2}\left(1-\nu^{i}\right) \gamma_{t, q}^{i}}{\left[\left[1-\alpha^{i}\left(1-\delta^{i}\right)\right] \nu^{i} \gamma_{t, q}^{i}+\frac{1}{2}\left(1-\nu^{i}\right)\right]^{2}}\right]
\end{aligned}
$$

For $q=0$,

$$
\left.\frac{\partial J_{t}^{i}}{\partial \alpha^{i}}\right|_{q_{t}^{i}=0}=2 \frac{Z_{t}^{i}}{V_{t-1}^{i}} \delta^{i}\left(1-\delta^{i}\right) \nu^{i}\left[\frac{\frac{1}{2}\left(1-\nu^{i}\right) \Omega_{t}^{i}}{\left[\alpha^{i}\left(1-\delta^{i}\right) \nu^{i} \Omega_{t}^{i}+\frac{1}{2}\left(1-\nu^{i}\right)\right]^{2}}\right]>0
$$

For $q \geq 1$, the sign depends on the values of the other parameters. As $q$ increases, the second term of (11) begins to dominate and the expression becomes negative. In particular, we can use infinity as an approximation for a large $q$ to show that the expression will become negative for all values of the other parameters (note that $\gamma_{t, q}^{i}$ approaches one as $q$ approaches infinity as all institutions have already bought the stock after an infinite number of good information event days).

$$
\lim _{q \rightarrow \infty} \frac{\partial J_{t}^{i}}{\partial \alpha^{i}}=2 \frac{Z_{t}^{i}}{V_{t-1}^{i}} \delta^{i}\left(1-\delta^{i}\right) \nu^{i}\left[-\frac{\frac{1}{2}\left(1+\nu^{i}\right)}{\left[\left[1-\alpha^{i}\left(1-\delta^{i}\right)\right] \nu^{i}+\frac{1}{2}\left(1-\nu^{i}\right)\right]^{2}}\right]<0
$$

Q.E.D

Proof of Result 5: The dispersion of a stock's price at any given date can be represented by the range $\frac{2 Z_{t}^{i}}{V_{t-1}^{i}}$. It is clear from expression (7) that an increase in $\frac{Z_{t}^{i}}{V_{t-1}^{i}}$ will intensify the effect of the information term on the asymmetry expression. If this term is positive, greater dispersion implies a more positive asymmetry expression. If this term is negative, greater dispersion implies a less positive asymmetry expression.

Q.E.D 


\section{References}

Allen, F., and G. Gorton, 1992, "Stock Price Manipulation, Market Microstructure and Asymmetric Information," European Economic Review, 36, 624-630.

Barnhart, B., 1997, "Investing in Mutual Funds," Chicago Tribune, July 27.

Bhattacharya, U., and M. Krishnan, 1999, "To Believe or Not to Believe," Journal of Financial Markets, 2, 69-98.

Blumstein, M., 1984, "How the Institutions Rule the Market," New York Times, November 25, p.1.

Bryant Quinn, J., 1997, "Trading Away the Strength of Mutual Funds," Washington Post, September 28.

Chan, L. K., and J. Lakonishok, 1993, "Institutional Trades and Intraday Stock Price Behavior," Journal of Financial Economics, 33, 173-199.

Chan, L. K., and J. Lakonishok, 1995, "The Behavior of Stock Prices Around Institutional Trades," Journal of Finance, 50, 1147-1174.

Chevalier, J., and G. Ellison, 1997, "Risk Taking by Mutual Funds as a Response to Incentives," Journal of Political Economy, 105, 1167-1200.

Del Guercio, D., and P. A. Tkac, 1998, "The Determinants of the Flow of Funds Managed Portfolios: Mutual Funds versus Pension Funds," working paper, University of Oregon.

Diamond, D. W., and R. E. Verrecchia, 1987, "Constraints on Short-Selling and Asset Price Adjustment to Private Information," Journal of Financial Economics, 18, 277-311.

Easley, D., N. M. Kiefer, and M. O'Hara, 1997a, "The Information Content of the Trading Process," Journal of Empirical Finance, 4, 159-186.

Easley, D., N. M. Kiefer, and M. O'Hara, 1997b, "One Day in the Life of a Very Common Stock," Review of Financial Studies, 10, 805-835.

Easley, D., and M. O'Hara, 1987, "Price, Trade Size, and Information in Securities Markets," Journal of Financial Economics, 19, 69-90.

Easley, D., and M. O'Hara, 1992, "Time and the Process of Security Price Adjustment," Journal of Finance, 47, 577-605.

Edelen, R. M., 1998, "Investor Flows and the Assessed Performance of Open-end Mutual Funds," working paper, University of Pennsylvania.

Falkenstein, E. G., 1996, "Preferences for Stock Characteristics as Revealed by Mutual Fund Portfolio Holdings," Journal of Finance, 51, 111-135. 
Gasparino, C., 1997, "Mutual Funds Show Managers The Money, Seeking Big Returns," Wall Street Journal, March 7.

Gemmill, G., 1996, "Transparency and Liquidity: A Study of Block Trades on the London Stock Exchange under Different Publication Rules," Journal of Finance, 51, 1765-1790.

Glosten, L., and P. Milgrom, 1985, "Bid, Ask and Transaction Prices in a Specialist Market with Heterogeneously Informed Traders," Journal of Financial Economics, 14, 71-100.

Grinblatt, M., and S. Titman, 1995, "Performance Evaluation," in Handbooks in Operations Research and Management Science Volume 9: Finance . pp. 581-609, Elsevier Science B.V., Amsterdam, The Netherlands.

Holthausen, R. W., R. W. Leftwich, and D. Mayers, 1987, "The Effect of Large Block Transactions on Security Prices," Journal of Financial Economics, 19, 237-267.

Holthausen, R. W., R. W. Leftwich, and D. Mayers, 1990, "Large-Block Transactions, the Speed of Response, and Temporary and Permanent Stock-Price Effects," Journal of Financial Economics, 26, 71-95.

Investment Company Act, 1940, 80a-18.

Keim, D. B., and A. Madhavan, 1994, "The Upstairs Market for Large-Block Transactions: Analysis and Measurement of Price Effects," Working paper (University of Pennsylvania).

Keim, D. B., and A. Madhavan, 1996, "The Upstairs Market for Large-Block Transactions: Analysis and Measurement of Price Effects," Review of Financial Studies, 9, 1-36.

Kraus, A., and H. R. Stoll, 1972, "Price Impacts of Block Trading on the New York Stock Exchange," Journal of Finance, 27, 569-588.

Lightfoot, L., P. Martin, M. Petersen, and E. R. Sirri, 1997, "Preferencing and Market Quality on U.S. Equity Exchanges," SEC working paper.

Lynch Koski, J., and R. Michaely, 1997, "Prices, Liquidity, and the Information Content of Trades," Manuscript.

Madhavan, A., and M. Cheng, 1997, "In Search of Liquidity: Block Trades in the Upstairs and Downstairs Markets," Review of Financial Studies, 10, 175-203.

Nocera, J., 1997, "Who Really Moves the Market?," Fortune Magazine, October 27.

Security and Exchange Commission, 1972, Investment Company Act of 1940, Release No. 7221.

Seppi, D. J., 1990, "Equilibrium Block Trading and Asymmetric Information," Journal of Finance, 45, 73-94. 
Seppi, D. J., 1992, "Block Trading and Information Revelation around Quarterly Earnings Announcements," Review of Financial Studies, 5, 281-305.

Sharpe, W. F., 1991, "Capital Asset Prices with and without Negative Holdings," Journal of Finance, 46, 489-509.

Smith, R., 1985, "Big-Block Trading Pits Institutions, Dealers in a Fast, Tough Game," Wall Street Journal, February 20, pp. 1,22.

Waggoner, J., 1997, "Mutual Funds Bid Up Pay of Senior Stock Analysts," USA Today, February 11. 


\section{Figure 1}

This figure depicts the probabilities and trading outcomes for an arbitrary stock. $\alpha^{i}$ is the probability of an information event. $\delta^{i}$ is the probability of bad information and $1-\delta^{i}$ is the probability of good information. $\nu^{i}$ is the probability that an institutional investor arrives to the market. $\gamma_{t, q}^{i}$ is the probability that the institutional investor's portfolio contains the stock. $\Omega_{t}^{i}$ is the probability that the institutional investor buys the stock on a good information day if the stock is not in its portfolio.

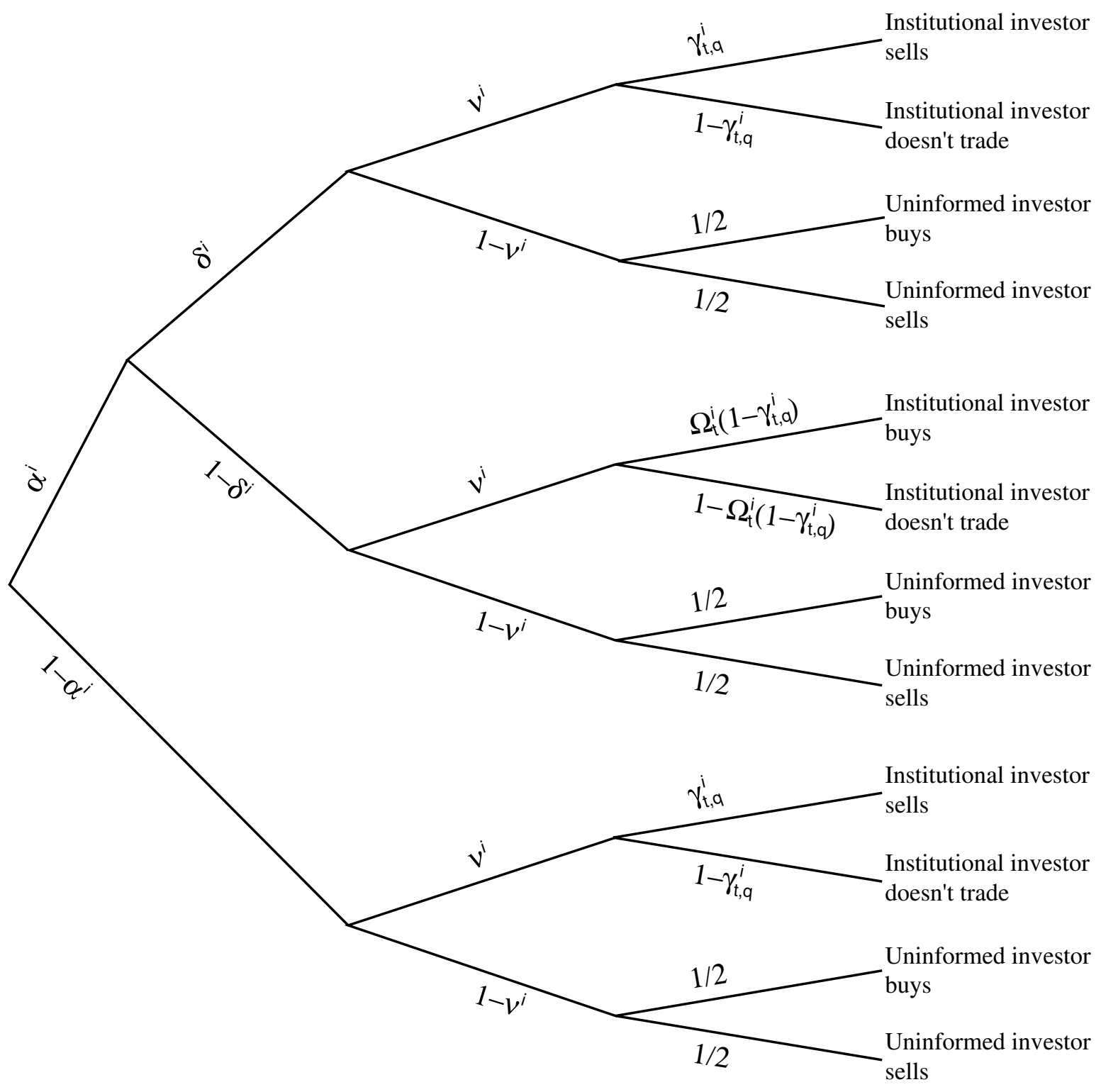

